\title{
PRIMER REPORTE DE Colletotrichum coccodes EN FRUTOS DE TOMATE (Solanum lycopersicum) EN MÉXICO
}

\section{FIRST REPORT OF Colletotrichum coccodes IN FRUITS OF TOMATO (Solanum lycopersicum) IN MEXICO}

\section{Daniel Nieto-Angel ${ }^{1 *}$, Alejandra Almaraz-Sánchez ${ }^{1}$, Victoria Ayala-Escobar ${ }^{1}$, Mario Orozco-Santos ${ }^{2}$ y Fracisco M. Lara-Viveros ${ }^{3}$}

\begin{abstract}
'Colegio de Postgraduados, Campus Montecillo, Posgrado en Fitosanidad-Fitopatología, Montecillo, Texcoco, Estado de México, México. ${ }^{2}$ Instituto Nacional de Investigaciones Forestales, Agrícolas y Pecuarias, Campo Experimental Tecomán, Tecomán, Colima, México. ${ }^{3}$ CONACyT Universidad Politécnica de Francisco I Madero, Tepatepec, Hidalgo, México..
\end{abstract}

*Autor de correspondencia (dnieto@colpos.mx)

\section{RESUMEN}

La antracnosis, ocasionada por Colletotrichum coccodes, afecta solanáceas y cucurbitáceas. En México este patógeno se ha reportado en el cultivo de papa (Solanum tuberosum L.), pero no en tomate (Solanum lycopersicum). En el año 2015 se observó la presencia del síntoma de lesiones hundidas con $7 \%$ de incidencia en frutos de tomate de muestras en campo abierto del estado de Morelos, México. El objetivo del presente estudio fue identificar al agente causal del síntoma de antracnosis en el fruto mediante características morfológicas y moleculares. El material colectado se desinfestó y sembró en medio de cultivo PDA (papa-dextrosa-agar) y agar-jugo V8, a partir de lesiones hundidas en las cuales se observó formación de esclerocios, setas, conidios cilíndricos, hialinos, sin septos, de 3.16 a $4.16 \mu \mathrm{m}$ de ancho y de 12.5 a $17.2 \mu \mathrm{m}$ de largo con apresorios lobulados. En la caracterización molecular, las secuencias obtenidas con los inciadores ITS5/ITS4 tuvieron una similitud del $100 \%$ con Collectotrichum coccodes. Las pruebas de patogenicidad se realizaron en frutos sanos con o sin herida y se evaluó el tamaño de la lesión cada $48 \mathrm{~h}$. Los síntomas iniciales aparecieron a las $72 \mathrm{~h}$ y a los $8 \mathrm{~d}$ presentaron lesiones desde 0.5 hasta $3.25 \mathrm{~cm}$ de diámetro. La prueba de Tukey detectó diferencias significativas entre métodos de inoculación. Este es el primer reporte de Collectotrichum coccodes que afecta frutos de tomate en México.

Palabras clave: Hongos, medios de cultivo, patogenicidad, antracnosis.

\section{SUMMARY}

Anthracnose, caused by Colletotrichum coccodes, affects solanaceae and cucurbits. In Mexico this pathogen has been reported in potato (Solanum tuberosum L.) cultivation, but not in tomato (Solanum lycopersicum). In 2015, the presence of symptom of deep-set lesions was observed with $7 \%$ incidence in tomato fruits sampled in open fields in the state of Morelos, Mexico. The objective of this study was to identify the causal agent of anthracnose symptom of the fruit by morphological and molecular characteristics. The collected material was disinfested and seeded in PDA (potato-dextrose-agar) culture medium and agar-V8 juice, from sunken lesions in which formation of sclerotia, mushrooms, cylindrical conidia, hyalines, without, septa of 3.16 to $4.16 \mu \mathrm{m}$ wide and 12.5 to $17.2 \mu \mathrm{m}$ long with lobed appressoria. In molecular characterization, the sequences obtained with the ITS5/ITS4 primers had 100 $\%$ similarity with Collectotrichum coccodes. The pathogenicity tests were carried out on healthy fruits with or without a wound and the lesion size was evaluated every $48 \mathrm{~h}$. The initial symptoms appeared at $72 \mathrm{~h}$ and at $8 \mathrm{~d}$ they presented lesions from 0.5 to $3.25 \mathrm{~cm}$ in diameter. The Tukey test detected significant differences between inoculation methods. This is the first report of
Collectotrichum coccodes that affects tomato fruits in Mexico.

Index words: Fungi, culture media, pathogenicity, anthracnose.

\section{INTRODUCCIÓN}

El tomate (Solanum lycopersicum), cuyo centro de domesticación es México, en la última década se ha colocado como la cuarta hortaliza en producción en el mundo, y es la más consumida después de la papa (Solanum tuberosum L.) (Blancard et al., 2011; FAOSTAT, 2015); sin embargo, en los últimos años se han desarrollado nuevas enfermedades. Dentro de los patógenos que pueden causar pérdidas económicas se encuentran nemátodos, bacterias (Hernández-Romano et al., 2019), virus, viroides, pero son los hongos, por su gran diversidad de especies y hospedantes, los más importantes a nivel mundial (Agrios, 2005).

Uno de los hongos fitopatógenos es Colletotrichum coccodes, que ha sido reportado en algunas regiones del mundo por afectar principalmente a solanáceas y cucurbitáceas (Tsror y Johnson, 2000). En el caso de las solanáceas, en papa ocasiona el síntoma denominado "punto negro", enfermedad que a principios de los 1990s era considerada de poca importancia; sin embargo, se reporta que ha causado grandes pérdidas en países como Israel y EUA (Barkdoll y Davis 1992; Tsror et al., 1994). C. coccodes causa el síntoma de antracnosis en tomate. Los síntomas iniciales aparecen en frutos maduros como manchas de color marrón claro, y a medida que la enfermedad avanza, las lesiones se agrandan y se observa un hundimiento. El hongo infecta a frutos a través de aberturas naturales; además, el mismo proceso se lleva a cabo a través de heridas ocasionadas por arena que transporta el viento (Piterková et al., 2009).

Cuando los frutos son verdes aún, el patógeno puede 
permanecer inactivo (infección quiescente) sobre el fruto hasta que éste alcanza la madurez fisiológica (Alkan et al., 2012). Dentro de las lesiones se pueden observar masas de conidios, aunque el hongo también puede atacar raíces, tallos y hojas. Los daños en frutos pueden afectar el $\mathrm{pH}$ en los tejidos, lo cual puede ser importante en términos económicos (Alkan et al., 2012; Dillard, 1992). Una de las características morfológicas importantes del hongo es la producción de esclerocios, los cuales pueden sobrevivir en residuos de cosecha o en el suelo, incluso por más de cinco años, y ser fuente de inóculo en campos donde no se realiza rotación de cultivos (Dillard y Cobb, 1998). La identificación precisa de un patógeno es esencial para reducir los efectos devastadores de la enfermedad mediante la aplicación de un manejo integrado del cultivo para disminuir los daños ocasionados por la enfermedad (Agrios, 2005; Blancard, 2011). Por lo anterior, el objetivo del presente trabajo fue determinar el agente causal de la antracnosis en frutos de tomate mediante técnicas morfológicas y moleculares.

\section{MATERIALES Y MÉTODOS}

\section{Recolecta de materiales y aislamiento de simbiontes}

En el año 2015, en el estado de Morelos, México, se observaron frutos de Solanum lycopersicum con incidencia del $7 \%$ de antracnosis; de estos materiales se recolectaron muestras con síntomas como lesiones hundidas y en algunos casos con signos del patógeno. En 60 frutos recolectados se realizaron cortes de tejido epidermal (incluídos tejido sano y enfermo), éste fue lavado con agua corriente y posteriormente desinfestado con hipoclorito de sodio $0.5 \%$ durante 5 min, después se enjuagó dos veces con agua destilada estéril y se dejó secar sobre toallas de papel estériles a temperatura ambiente bajo condiciones asépticas en una cámara de flujo laminar. El tejido se sembró en medio de cultivo PDA (papa-dextrosa-agar) y agar-jugo V8, se incubó a $27 \pm 2{ }^{\circ} \mathrm{C}$ bajo lámparas de luz blanca hasta el desarrollo de los hongos. La purificación de los cultivos se realizó mediante obtención de cultivos monoconidiales en medio de cultivo PDA de 7 a $10 \mathrm{~d}$ bajo las mismas condiciones de luz

\section{Pruebas de patogenicidad}

Se utilizaron 54 frutos sanos de tomate, los cuales se desinfestaron con solución de hipoclorito de sodio $0.5 \%$ durante $5 \mathrm{~min}$. Posteriormente, se sumergieron en agua destilada estéril durante 5 min, se colocaron sobre toallas de papel estéril y se dejaron secar a temperatura ambiente. De cada aislamiento se inocularon tres frutos con discos de $5 \mathrm{~mm}$ de diámetro que contenían al patógeno de $8 \mathrm{~d}$ de edad contados después de la siembra en medio de cultivo PDA. Se realizaron dos tipos de inoculación: 1) con herida (punción con aguja) y 2) sin herida. Los frutos se colocaron en charolas de unicel dentro de bolsa de plástico para proporcionar condiciones de humedad de 90 $\%$ y temperatura ambiente de $25 \pm 2{ }^{\circ} \mathrm{C}$; posteriormente, cada 48 h se midió el diámetro de la lesión. Finalmente, de los 60 frutos colectados se obtuvieron ocho aislamientos con clave 1A, 2A, 2B, 3, 4, 6A, 6B y 7 . Los aislamientos se conservaron en glicerol al $30 \%$ y se almacenaron en congelación para su posterior uso.

\section{Caracterización morfológica}

Se registraron variables como color de la colonia, tipo de micelio, crecimiento en la colonia en la caja Petri, morfología y tamaño de los conidios, apresorios, setas y presencia o ausencia de gútulas en los ocho aislamientos con tres repeticiones por cada uno. Se midió el diámetro de la colonia cada 48 h hasta que el hongo llenó la caja por completo. Para la medición de conidios se realizaron preparaciones permanentes en glicerol $50 \%$. Con ayuda del microscopio compuesto y del programa Motic Images Plus 2.0 (Group Co., Ltd) se midió el ancho y largo de 100 conidios de cada uno de los aislamientos. Para observar los apresorios se realizaron preparaciones temporales de cada aislamiento, se colocó una masa de micelio con conidios en agua destilada estéril sobre un portaobjetos, los cuales se mantuvieron en cámara húmeda durante 24 h a $27 \pm 2{ }^{\circ} \mathrm{C}$.

\section{Caracterización molecular}

Una vez obtenidos los aislamientos puros en cultivo monospórico, se inició el análisis molecular con la extracción de ADN genómico de los aislamientos fúngicos identificados morfológicamente como pertenecientes al género Colletotrichum, para lo cual se utilizó el kit de extracción PlantDNeasy ${ }^{\circledR}$ Minikit (Quiagen) de acuerdo con las instrucciones del fabricante. La reacción PCR se llevó a cabo con los oligonucleótidos ITS4 (5'-TCCTCCGCTTATTGATATGC- $\left.3^{\prime}\right)$ e ITS5 (5'-GGAAGTAAAAGTCGTAACAAGG-3') (White et al. 1990). Las condiciones consistieron en desnaturalización inicial de 5 min a $94{ }^{\circ} \mathrm{C}, 40$ ciclos de $30 \mathrm{~s}$ a $94^{\circ} \mathrm{C}, 30 \mathrm{~s}$ a $52^{\circ} \mathrm{C}$, $30 \mathrm{~s} \mathrm{a} 72{ }^{\circ} \mathrm{C}$ y amplificación final por $7 \mathrm{~min}$ a $72^{\circ} \mathrm{C}($ Damm et al., 2009). Los productos de la PCR se procesaron en el laboratorio de Macrogen Inc. (Corea del Sur) para su secuenciación.

\section{Análisis de la información}

En el caso de la caracterización morfológica se aplicó análisis de varianza y para la comparación de medias se utilizó la prueba de Tukey $(P \leq 0.05)$ mediante el programa 
SAS versión 9.0 para Windows.

Para la caracterización molecular los resultados obtenidos se compararon en la base de datos del Centro Nacional para la Información Biotecnológica (NCBI por sus siglas en inglés) con la herramienta BioEdit v7.0.9. (Hall, 1999). Las secuencias que presentaron similitud se utilizaron para la construcción de un árbol filogenético con el programa MEGA X (Kumar et al., 2018).

\section{RESULTADOS Y DISCUSIÓN}

\section{Pruebas de patogenicidad}

Los primeros síntomas del hongo se observaron $3 \mathrm{~d}$ después de la inoculación (ddi), éstos fueron más visibles en frutos inoculados con herida artificial, mientras que en frutos sin herida sólo en algunos casos se observaron síntomas (Figura 1). A los 8 ddi todos los aislamientos fueron patogénicos al ocasionar lesiones de 0.6 a 3.5 $\mathrm{cm}$ de diámetro. En todos los casos el patógeno causó lesiones hundidas y presentó características particulares como masas negras (acérvulos), rajaduras o rompimiento de la epidermis entre los 4 y $6 \mathrm{~d}$. En las pruebas de patogenicidad no hubo diferencia en cuanto a los días de aparición de síntomas (3 ddi) y diámetro de lesión (0.5 a $3.5 \mathrm{~cm}$ ) a los $8 \mathrm{ddi}$. Estos resultados son comparables con lo reportado por Alkan et al. (2012), quienes encontraron que al inocular frutos de tomate con C. coccodes mediante herida artificial los primeros síntomas aparecen a los 4 ddi con lesiones de 0.4 a $3.5 \mathrm{~cm}$ de diámetro a los 7 ddi.

En cuanto a síntomas como lesiones circulares, hundidas y con aparición de signos del patógeno desde los 3 ddi, éstos fueron similares a lo reportado por otros autores (Alkan et al., 2012; Dillard y Cobb, 1998; Gleason y Edmunds, 2006; Li, 2013).

Estadísticamente no se encontraron diferencias significativas en patogenicidad entre aislamientos, pero sí las hubo en cuanto al método de inoculación (Cuadro 1); cuando la inoculación se realizó a través de una herida
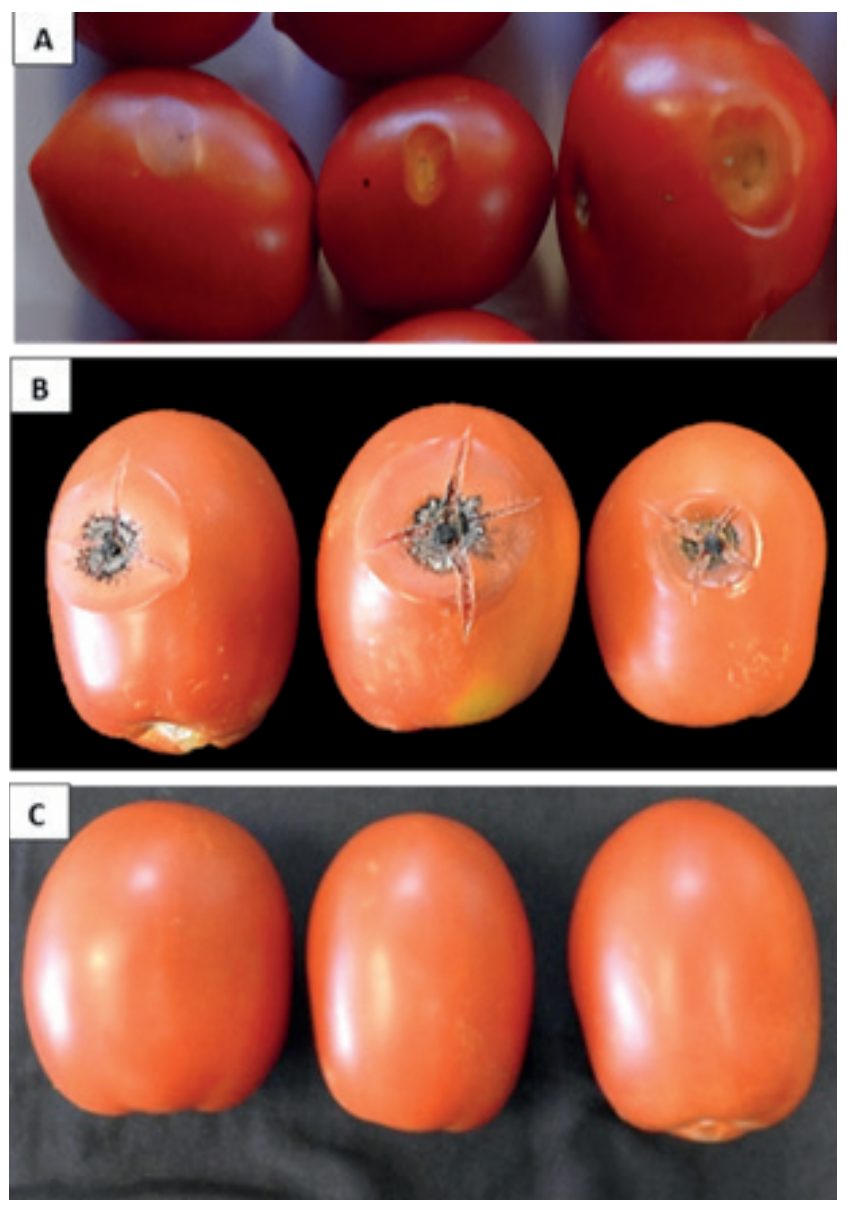

Figura 1. A) Frutos colectados de campo con lesiones, B) Síntomas observados ocho dias después de la inoculación, C) Frutos testigos de tomate asintomáticos. 
artificial todos los frutos inoculados presentaron lesión y ésta fue de mayor diámetro, a diferencia de la inoculación sin herida, donde se observó que sólo siete de 24 frutos presentaron síntomas. Aunque el patógeno puede infectar frutos en ausencia de heridas mediante la formación de apresorios, el ataque de insectos, las aberturas naturales y las heridas facilitan la infección del hongo (De Lapeyre de Bellaire, 2000; Gleason y Edmunds, 2006; Prusky, 1996; Rodríguez et al., 2009).

\section{Características morfológicas}

En cuanto al desarrollo de los hongos en medio de cultivo PDA y agar-jugo V8, se pudo observar que siete aislamientos desarrollaron micelio blanco aéreo, formación de esclerocios y anillos concéntricos (Figura 2). El aislamiento $2 \mathrm{~B}$ sólo desarrolló micelio blanco y no presentó formación de esclerocios ni anillos concéntricos. Con respecto a la velocidad de crecimiento del patógeno en medio cultivo, se observó que éste fue más lento en el presente estudio en comparación con lo reportado por Cano et al. (2004), quienes observaron mayor diámetro de crecimiento por día en medio PDA y PCA (papa-zanahoriaagar), aunque sus aislamientos fueron incubados a
$25{ }^{\circ} \mathrm{C}$ durante $12 \mathrm{~h}$ de oscuridad alternados con $12 \mathrm{~h}$ de luz cercana a la ultravioleta, mientras que para esta investigación se utilizó medio PDA y agar-jugo V8 y se incubó a $27 \pm 2{ }^{\circ} \mathrm{C}$ con lámparas de luz blanca.

Se observó la presencia de setas, conidios cilíndricos, hialinos, sin septos, en ocasiones con la presencia de crecimiento citoplasmático o gútulas con dimensiones de 3.16 a $4.16 \mu \mathrm{m}$ de ancho y de 12.5 a $17.2 \mu \mathrm{m}$ de largo. Se observaron apresorios ovalados, elípticos y lobulados (Figura 3). Estas características corresponden a la especie C. coccodes, de acuerdo con las claves de Sutton (1980). En cuanto a las características morfológicas de los conidios, éstas son similares a las reportadas por Cano et al. (2004). En otro estudio se reportaron características similares en medio de cultivo PDA, aunque el aislamiento correspondió al patógeno de pimiento (Capsicum annuum) (Stoyanova et al., 2013).

\section{Identificación filogenética}

Al comparar los resultados de los ocho aislamientos de Colletotrichum con la base de datos del GenBank se encontró $100 \%$ de similitud con Colletotrichum coccodes, por lo que se tomó un aislamiento representativo y se

Cuadro 1. Diámetro de lesiones Colletotrichum coccodes ocho dias después de la inoculación en frutos de tomate (Solanum lycopersicum).

\begin{tabular}{|c|c|c|c|c|c|c|c|c|c|}
\hline \multirow{2}{*}{ Tratamiento } & \multicolumn{8}{|c|}{ Aislamiento } & \multirow[t]{2}{*}{ Media } \\
\hline & $1 \mathrm{~A}$ & $2 \mathrm{~A}$ & $2 B$ & 3 & 4 & $6 \mathrm{~A}$ & $6 B$ & 7 & \\
\hline Herida & $1.92 \mathrm{a}$ & $3.60 \mathrm{a}$ & $1.31 \mathrm{a}$ & $1.69 \mathrm{a}$ & $3.44 \mathrm{a}$ & $2.78 \mathrm{a}$ & $3.25 \mathrm{a}$ & $2.56 \mathrm{a}$ & $2.57 \mathrm{a}$ \\
\hline Sin herida & $0.14 \mathrm{a}$ & 0.83 a & $0.09 a$ & $0 \mathrm{a}$ & $1.3 \mathrm{a}$ & 0.8 a & $0 \mathrm{a}$ & 0.93 a & $0.51 \mathrm{~b}$ \\
\hline
\end{tabular}

Valores con la misma letra dentro de filas para los aislamientos, son estadísticamente iguales (Tukey, $\mathrm{P} \leq 0.05)$. En la columna de la extrema derecha, valores con diferente letra son estadísticamente diferentes (Tukey P $\leq 0.05$ ).
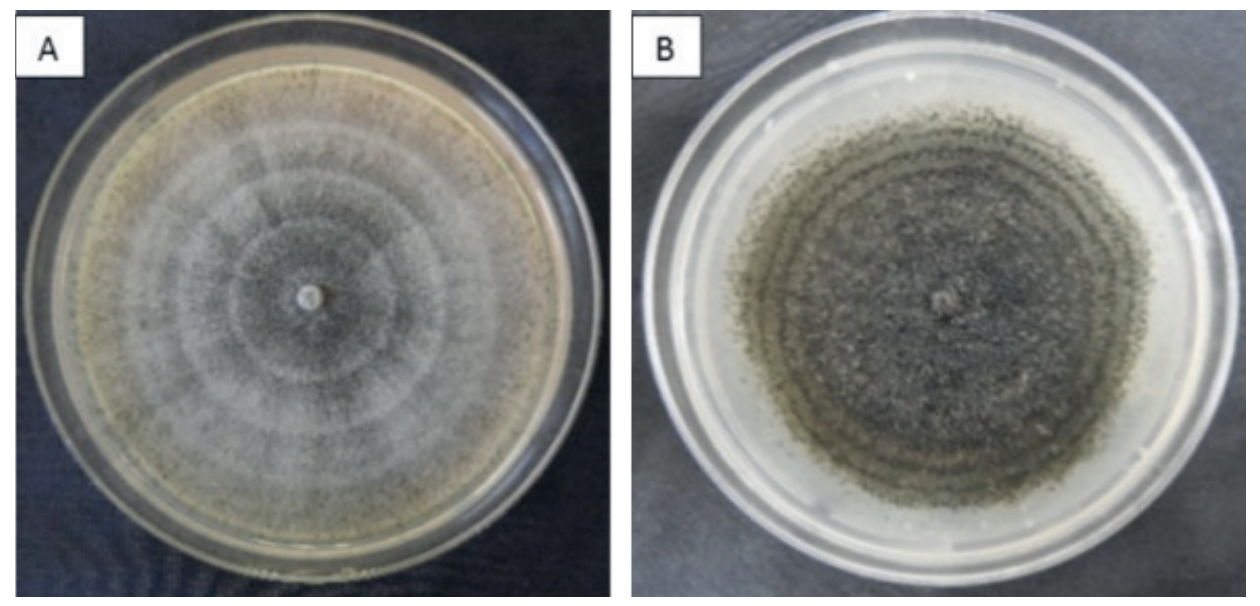

Figura 2. Colonias de Colletotrichum coccodes crecidas en medios de cultivo: A) agar-jugo V8 y B) papa dextrosa-agar a los 12 dias de edad. 

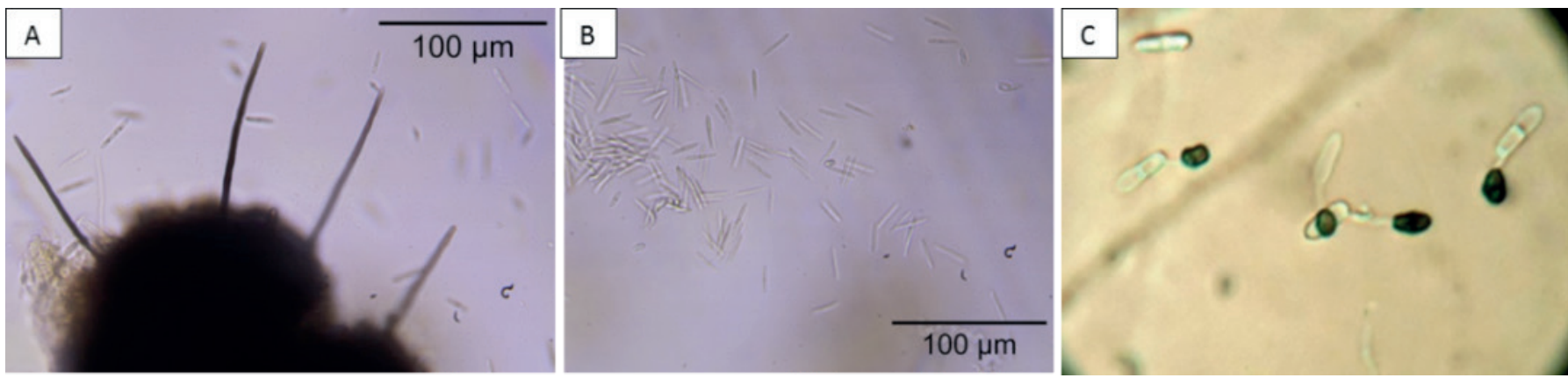

Figura 3. A) Acérvulo con setas; B) Conidios hialinos cilíndricos, sin septos gutulados de Colletotrichum coccodes; C) Formación de apresorios melanizados de color café oscuro, de forma globosa a irregular de 24 h. Magnificación 40x.

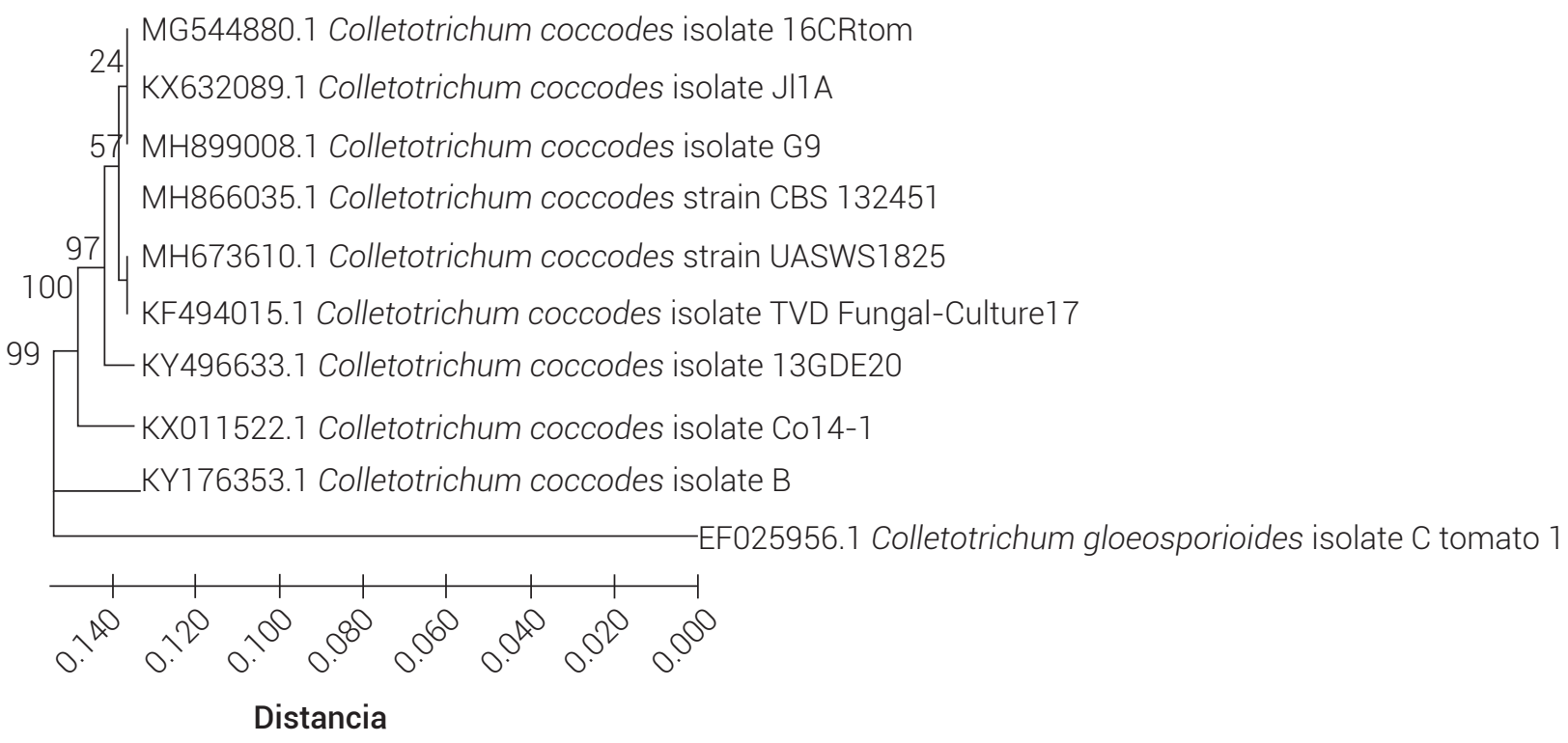

Figura 4. Árbol filogenético con la agrupación de nueve aislamientos de Colletotrichum coccodes basado en las secuencias de primers ITS, construido con el programa MEGA X mediante el método UPGMA.

realizó una secuencia consenso que fue depositada en el GenBank con número de accesión (KX632089) y se comparó con nueve secuencias del Banco de Genes del CNBI (Figura 4). Anteriormente la identificación de los hongos se realizaba mediante claves taxonómicas; sin embargo, en la actualidad se utiliza la reconstrucción filogenética para la identificación a nivel de especie (Guerber et al., 2003).

\section{CONCLUSIONES}

Con base en la morfología y reconstrucción filogenética se considera a $C$. coccodes como el causante del síntoma de antracnosis en frutos de tomate. En las pruebas de patogenicidad se observaron lesiones hundidas y signos del patógeno con manifestaciones en forma de masas negras (acérvulos), rajaduras o rompimiento de la epidermis. La aparición de síntomas y tamaño de lesión fue mayor en frutos inoculados mediante una herida. Este es el primer reporte de $C$. coccodes que afectó a frutos de tomate en México.

\section{BIBLIOGRAFÍA}

Agrios G. N. (2005) Plant Pathology. 5th edition. Academic Press. San Diego, California, USA. 952 p.

Alkan N., R. Fluhr and D. Prusky (2012) Amonium secretion during Colletotrichum coccodes infection modulates salicilyc and jasmonic acid pathways of ripe and unripe tomato fruit. Molecular Plant-Microbe Interactions 25:85-96, https://doi.org/10.1094/mpmi-01-11-0020 
Barkdoll A. W. and J. R. Davis (1992) Distribution of Colletotrichum coccodes in Idaho and variation in pathogenicity on potato. Plant Disease 76:131-135, https://doi.org/10.1094/PD-76-0131

Blancard D., H. Laterrot, G. Marchoux y T. Candresse (2011) Enfermedades del Tomate: Identificar, Conocer, Controlar. Mundi-Prensa. Madrid, España. 679 p.

Cano J., J. Guarro and J. Gené (2004) Molecular and morphological identification of Colletotrichum species of clinical interest. Journal of Clinical Microbiology 42:2450-2454 https://doi.org/10.1128/JCM.42.6.2450-2454.2004

Damm U., J. H. Woudenberg, P. F. Cannon and P. W. Crous (2009) Colletotrichum species with curved conidia from herbaceous hosts. Fungal Diversity 39:45-87.

De Lapeyre de Bellaire L., M. Chillet, C. Dubois and X. Mourichon (2000) Importance of different sources of inoculum and dispersal methods of conidia of Colletotrichum musae, the causal agent of banana anthracnose, for fruit contamination. Plant Pathology 49:782-790, https://doi.org/10.1046/j.1365-3059.2000.00516.x

Dillard H. R. (1992) Colletotrichum coccodes: the pathogen and its hosts. In: Colletotrichum: Biology, Pathology, and Control. J. A. Bailey and M. J. Jeger (eds.). CAB International. Wallingford, UK. pp:225-236

Dillard H. R. and A. C. Cobb (1998) Survival of Colletotrichum coccodes in infected tomato tissue and in soil. Plant Disease 82:235-238, https://doi.org/10.1094/PDIS.1998.82.2.235

FAOSTAT, Organización de las Naciones Unidas para la Alimentación y la Agricultura, División Estadística (2015) Datos sobre alimentación y agricultura. Cultivos. Organización de las Naciones Unidas para la Alimentación y la Agricultura. Roma. http://www.fao. org/faostat/es/\#data/QC (Noviembre 2016).

Gleason M. L. and B. A. Edmunds (2006) Tomato diseases and disorders. University Extension PM 1266. lowa State University Press. Ames, Iowa, USA. 12 p.

Guerber J. C., B. Liu, J. C. Correll and P. R. Johnston (2003) Characterization of diversity in Colletotrichum acutatum sensu lato by sequence analysis of two gene introns, mtDNA and intron RFLPs, and mating compatibility. Mycologia 95:872-895, https://doi.org/10.2307/3762016

Hall T. A. (1999) BioEdit: a user-friendly biological sequence alignment editor and analysis program for Windows 95/98/NT. Nucleic Acids Symposium Series 41:95-98.

Hernández-Romano J., L. A. Mastache-Estrada, D. A. Molina-Sánchez, R. Serrano-Plancarte, C. Peña-Barrera, M. I. Chávez-Bejar, N. Romero-
Martínez y A. N. Lecona-Valera (2019) Estabilidad y capacidad inhibitoria del bacteriófago opRS, agente potencial para el biocontrol de Ralstonia solanacearum. Revista Fitotecnia Mexicana 42:13-19.

Kumar S., G. Stecher, M. Li, C. Knyaz and K. Tamura (2018) MEGA X: Molecular evolutionary genetics analysis across computing platforms. Molecular Biology and Evolution 35:1547-1549, https://doi.org/10.1093/molbev/msy096

Li Y. H. (2013) Anthracnose of tomato. The Connecticut Agricultural Experiment Station. New Haven, Connecticut, USA. $2 \mathrm{p}$

Piterková J., M. Petřivalský, L. Luhová, B. Mieslerová, M. Sedlárová and A. Lebeda (2009) Local and systemic production of nitric oxide in tomato responses to powdery mildew infection. Molecular Plant Pathology 10:501-513, https://doi.org/10.1111/j.1364-3703.2009.00551.x

Prusky D. (1996) Pathogen quiescence in postharvest diseases Annual Review of Phytopathology 34:413-434, https://doi org/10.1146/annurev.phyto.34.1.413

Rodríguez-López E. S., J. M. González-Prieto y N. Mayek-Pérez (2009) La infección de Colletotrichum gloeosporioides (Penz.) Penz. y Sacc. en Aguacatero (Persea americana Mill.): aspectos bioquímicos y genéticos. Revista Mexicana de Fitopatología 27:53-63.

Stoyanova Z. B., R. M. Rodeva, I. Karov, B. Kovacevik, V. I. Manova and R. G Georgieva (2013) Morphological and molecular characterization of Colletotrichum coccodes isolated from pepper cultivated in Bulgaria and Macedonia. Journal of Natural Science 124:249261, https://doi.org/10.2298/ZMSPN1324249S

Sutton B. C. (1980) The Coelomycetes: Fungi Imperfeti with Pycnidia Acervuli and Stromata. Commonwealth Mycological Institute. Kew, England. $696 p$

Tsror L. and D. A. Johnson (2000) Colletotrichum coccodes on potato. In: Colletotrichum: Host Specificity, Pathology, and Host-Pathogen Interactions. D. Prusky, S. Freeman and M. B. Dickman (eds.) American Phytopathological Society Press. St. Paul, Minnesota. USA. pp:362-373.

Tsror L., O. Erlich, M. Hazanovsky and I. Peretz (1994) Colletotrichum on potato in Israel, is it a new disease? Parasitica 22:88.

White T. J., T. Bruns, S. Lee and J. Taylor (1990) Amplification and direct sequencing of fungal ribosomal RNA genes for phylogenetics. In: PCR Protocols: A Guide to Methods and Applications. M. A Innis, D. H. Gelfand, J. J. Sninsky and T. J. White (eds). Academic Press. New York, USA. pp:315-322. 